\title{
Procesos de urbanización turística. Aproximación cualitativa al contexto ideológico*
}

\section{Alejandro Mantecón}

Universidad de Alicante. Departamento de Sociología I y Teoría de la Educación

Edificio de Ciencias Sociales, 2a planta

Ap. 99. Campus de San Vicente del Raspeig. Alicante

alejandro.mantecon@ua.es

\section{Resumen}

Las relaciones entre el turismo y las dinámicas residenciales han sido estudiadas atendiendo a los contextos sociodemográfico, económico, geográfico o medioambiental en los que éstas han tenido lugar. Sin embargo, son escasos los trabajos en los que se propone un análisis del contexto ideológico. Este artículo trata de realizar una aportación al análisis de las dimensiones ideológicas del fenómeno turístico-residencial, pues su explicación puede ofrecer claves sociológicas que ayuden a comprender su dinámica. Aquí se lleva a cabo una aproximación cualitativa a los discursos producidos por las elites políticas, los agentes económicos fundamentales, los expertos y la ciudadanía.

Palabras clave: turismo, urbanización, contexto ideológico, legitimación, investigación cualitativa.

Abstract. Urbanisation processes in tourist areas. A qualitative approach to their ideological context

The connections between tourism and residential trends have been explored bearing in mind the socio-demographic, economic, geographical, or environmental context in which they have taken place. However, few studies have studied their ideological context. This paper tries to contribute to the analysis of the ideological elements present in residential tourism, as they can provide us with valuable sociological keys to understanding the development of this phenomenon. This is a qualitative approach to the discourses of the political elites, the main economic agents, the experts, and the citizens of tourist areas.

Key words: tourism, urbanisation, ideological context, legitimation, qualitative research.

* Este artículo es el resultado del trabajo realizado en la tesis doctoral del autor y se enmarca ahora en dos proyectos de I+D: Problemas en la legitimación ciudadana del turismo residencial (SEJ2006-14620/SOCI, del MEC) y La percepción social del desarrollo turístico-residencial (AE/2007/070, de la Generalitat Valenciana), ambos dirigidos por Tomás Mazón. 


\section{Sumario}

\section{Introducción}

2. Aproximación al turismo residencial

3. Objetivo y metodología

4. El contexto ideológico: la legitimación

como hilo conductor
5. A modo de conclusión: nuevas líneas de trabajo

Referencias bibliográficas

\section{Introducción}

Recientemente, a propósito de la publicación de su trabajo La localización de la población española sobre el territorio, Matilde Mas y Francisco Goerlich eran preguntados sobre el futuro del modelo urbano de la Comunidad Valenciana. Según estos investigadores: «lo que por ahora no se aprecia es el agotamiento de la demanda en la costa. Eso sigue siendo un potentísimo foco de atracción de la población al que no le veo final. El final ni siquiera llegará cuando ya esté todo construido, ya que entonces la población se irá desplazando hacia los valles del interior» (Mas y Goerlich, 2006b: 14). El futuro de las poblaciones costeras mediterráneas parece estar ligado a los desarrollos turístico-residenciales. La proliferación de viviendas secundarias mantiene, en el caso español, una relación evidente con el desarrollo del turismo residencial. El censo de 2001 revelaba que las diez provincias que concentran más viviendas secundarias agrupan al $42 \%$ del total estatal. Son, en orden decreciente, Madrid, Alicante, Valencia, Barcelona, Málaga, Tarragona, Gerona, Murcia, Palma de Mallorca y Castellón. Aunque no todas están destinadas a un uso turísticoresidencial, sí que parece que su fin último se ve determinado por localizarse en un contexto turístico, pues la mayor parte se hallan en las ciudades del litoral.

En este artículo, la atención se centra en el caso configurado por los municipios turísticos de la costa alicantina, donde han tenido lugar dos desarrollos distintos. Por un lado, el caso de Benidorm, una ciudad dedicada a la industria del ocio en la que el turismo hotelero tiene una presencia mayor que en cualquier otro lugar. Por otro lado, puede hallarse lo que se ha convenido en llamar «turismo residencial», redefinido por algunos autores como «turismo inmobiliario", para enfatizar sus vínculos con la actividad especulativo-urbanística que constituye la construcción y la venta de urbanizaciones (Mazón, 2002), o como "modelo suburbano extensivo", para contraponer un modelo basado en la gestión del territorio a otro sustentado en la venta de su espacio de calidad (Iribas, 2000: 111). En el litoral alicantino, la mayoría de los municipios se han decantado por apoyar su desarrollo socioeconómico sobre el turismo residencial. Una opción que también ha triunfado en la mayor parte de los destinos turísticos de las costas españolas. En la provincia de Alicante se construyeron unas 350.000 nuevas viviendas turísticas entre 1960 y 2000 , lo cual generó un «modelo de oferta cuyo eje han sido los promotores inmobiliarios, no los turísticos, guiados en su mayoría por intereses especulativos» (Mazón, 2001: 265). 


\section{Aproximación al turismo residencial}

Pero ¿qué es el «turismo residencial»? Bajo esta expresión se esconde un conjunto de procesos de difícil delimitación en los que se entremezcla la actividad económica que gira en torno al negocio inmobiliario con elementos del turismo tradicional y éstos, a su vez, con algunas de las formas migratorias y de residencialidad emergentes en las últimas décadas en Occidente. Procesos que han sido situados por los investigadores en el marco teórico de las líneas de investigación sobre las migraciones internacionales de retirados y los estilos de vida transnacionales (O'Reilly, 2000; Gustafson, 2001), el estudio de las «sociedades móviles» (Salvà, 2005; Urry, 2002), las tendencias de contraurbanización (Ferrás, 2000) o los estudios sobre los procesos de integración europea (Schriewer y García, 2005). Antes de intentar realizar una definición más precisa, se comentan algunos datos que pueden ayudar a entender la naturaleza de este fenómeno social.

El contexto socioturístico alicantino se esboza en referencia a cinco municipios significativos: Denia, Altea, Benidorm, Santa Pola y Torrevieja. El desarrollo del turismo desde finales de los años cincuenta ha transformado completamente el entorno físico y social de estas poblaciones, que, como se aprecia en las tablas 1 y 2 , se sostienen hoy en la actividad constructora e inmobiliaria que rodea a las segundas residencias. El sector hotelero y la hostelería tienen un papel menor. No sorprende, entonces, que se hable del «triunfo del sector inmobiliario turístico sobre el turístico stricto sensu» (Bote, Marchena y Santos, 1999: 192). Benidorm, la excepción, es un modelo mixto con una oferta hotelera y hostelera de la que carecen los otros municipios.

La descompensación entre la oferta hotelera y la extrahotelera es concluyente. Los casos de Torrevieja y de Santa Pola son los más llamativos, sus pla-

Tabla 1. Alojamiento turístico

\begin{tabular}{|c|c|c|c|c|c|c|c|c|}
\hline & & Hotelería & $\begin{array}{l}\% \\
\text { del total }\end{array}$ & $\begin{array}{l}\text { Oferta } \\
\text { extrahotel. }\end{array}$ & $\begin{array}{l}\% \\
\text { del total }\end{array}$ & Cámping & $\begin{array}{l}\% \\
\text { del total }\end{array}$ & Total \\
\hline \multirow[t]{2}{*}{ Denia } & Unidades & 16 & & 23.029 & & 4 & & 23.049 \\
\hline & Plazas & 1.904 & 1,94 & 94.419 & 96,30 & 1.724 & 1,76 & 98.047 \\
\hline \multirow[t]{2}{*}{ Altea } & Unidades & 7 & & 6.555 & & 1 & & 6.563 \\
\hline & Plazas & 1.229 & 4,25 & 26.875 & 92,97 & 803 & 2,78 & 28.907 \\
\hline \multirow[t]{2}{*}{ Benidorm } & Unidades & 128 & & 32.799 & & 10 & & 32.937 \\
\hline & Plazas & 39.026 & 21,28 & 134.475 & 73,29 & 9.977 & 5,43 & 183.478 \\
\hline \multirow[t]{2}{*}{ Santa Pola } & Unidades & 4 & & 26.569 & & 1 & & 26.574 \\
\hline & Plazas & 825 & 0,74 & 108.933 & 98,03 & 1.365 & 1,23 & 111.123 \\
\hline \multirow[t]{2}{*}{ Torrevieja } & Unidades & 13 & & 80.790 & & 2 & & 80.805 \\
\hline & Plazas & 1.643 & 0,49 & 331.239 & 99,11 & 1.338 & 0,40 & 334.220 \\
\hline
\end{tabular}

Fuente: elaboración propia a partir de la Agencia Valenciana de Turismo (2006) y el INE (2001). 
Tabla 2. Empresas y empleo ligados directamente a los sectores del turismo y la vivienda

\begin{tabular}{ll|rc|rc}
\hline & & \multicolumn{2}{|c|}{ Construcción y actividades inmobiliarias } & \multicolumn{2}{c}{ Hostelería } \\
\hline Denia & Empresas & 512 & $22,9 \%$ & 292 & $12,7 \%$ \\
& Empleados & 2.497 & $25,2 \%$ & 1.396 & $14,1 \%$ \\
\hline Altea & Empresas & 290 & $23,6 \%$ & 182 & $14,8 \%$ \\
& Empleados & 1.273 & $25,4 \%$ & 621 & $12,4 \%$ \\
\hline Benidorm & Empresas & 597 & $14,8 \%$ & 788 & $19,6 \%$ \\
& Empleados & 3.097 & $13,9 \%$ & 8.808 & $39,5 \%$ \\
\hline \multirow{2}{*}{ Santa Pola } & Empresas & 204 & $21,0 \%$ & 160 & $16,5 \%$ \\
& Empleados & 793 & $18,8 \%$ & 708 & $16,8 \%$ \\
\hline Torrevieja & Empresas & 851 & $28,5 \%$ & 507 & $16,9 \%$ \\
& Empleados & 3.886 & $26,9 \%$ & 2.048 & $14,2 \%$ \\
\hline
\end{tabular}

Fuente: elaboración propia a partir de la Tesorería General de la Seguridad Social (2006).

zas hoteleras apenas suponen el 0,49 y el 0,74\% de la oferta de alojamiento, al tiempo que las de las segundas residencias se sitúan en el 99,11 y en el 98,03\% respectivamente. El cambio social ha sido inmenso. Uno de los índices más llamativos quizá sea el de aloctonía: en Denia, Altea y Santa Pola supera el $60 \%$ y en Benidorm y Torrevieja el $80 \%$.

El concepto "turismo residencial», que en su formulación ya plantea una contradicción difícil de asimilar, ha sido definido de varias maneras. Vicente Rodríguez (2004: 235-236) reconoce una mezcla de cuatro elementos formada por: a) un grupo humano con una presencia mayoritaria de personas mayores; $b$ ) que mantiene un comportamiento móvil oscilante entre la migración permanente, la temporal y la mera movilidad; c) con una motivación turística primaria consistente en la búsqueda de experiencias y el disfrute del tiempo libre, y d) que provoca impactos muy diversos, hasta dar lugar a un conjunto de categorías de difícil sistematización. López de Lera (1995: 234-237) identifica, en el turismo residencial protagonizado por los «viejos europeos retirados», uno de los flujos inmigratorios principales que tienen lugar en España. Tomás Mazón y Antonio Aledo (2005: 18-19) lo definen como «la actividad económica que se dedica a la urbanización, construcción y venta de viviendas turísticas residenciales que conforman el sector extrahotelero, cuyos usuarios las utilizan para veranear o residir, de forma permanente o semipermanente, fuera de sus lugares de residencia habitual, y que responden a nuevas fórmulas de movilidad y residencialidad de las sociedades avanzadas». Las «viviendas turísticas residenciales» son el subconjunto más relevante de las «viviendas secundarias», aquéllas que «se utilizan, sólo parte del año, de forma estacional, periódica o esporádica, por ejemplo, en vacaciones, fines de semana...» (Cortina, Martínez y Varela, 2002: 95). Estas definiciones sólo aclaran algunas de las 
dimensiones de un fenómeno conceptualmente difícil de acotar. Por un lado, la actividad urbanística ligada a la construcción de segundas residencias en lugares próximos a los espacios turísticos y, por otro, la movilidad de carácter en parte turístico y en parte migratorio asociada a una idea de búsqueda de ocio se revelan como las claves fundamentales. El turismo residencial es definido aquí como un proceso de reasentamiento temporal de la población en viviendas secundarias emplazadas en contextos turísticos (o en su proximidad) en las que sus ocupantes viven desde unos días al año hasta más meses de los que pasan en las viviendas consideradas principales. Estas viviendas secundarias, tendentes a concentrarse en urbanizaciones con edificaciones de baja altura, son identificadas por sus residentes con un espacio de la vida cotidiana en el que el tiempo libre y de ocio es el dominante. La búsqueda del ocio en un espacio-tiempo diferente al habitual les une a los turistas tradicionales, aunque los «residenciales» siguen una pauta de comportamiento más similar a la población local que a la turística (principalmente, menor inclinación al gasto -más allá de la adquisición y el acondicionamiento de la vivienda_, mayor duración de la estancia y menor número de desplazamientos en la región de referencia). Los llamados «turistas residenciales» del Mediterráneo español son, mayoritariamente, jubilados procedentes del interior y del norte del país o de la UE que, normalmente, no se ven a sí mismos como turistas, sino como residentes europeos, inversores o ciudadanos con varias viviendas o varios «hogares» ${ }^{1}$.

\section{Objetivo y metodología}

El fenómeno turístico-residencial ha sido estudiado atendiendo a los contextos demográfico, socioeconómico o geoambiental en los que se ha desarrollado, pero no existen trabajos en los que se analice el contexto ideológico. Aquí se presenta un estudio exploratorio que, en alguna medida, palia esa ausencia. El hilo conductor es la comprensión del proceso de legitimación del desarrollo turístico-residencial, es decir, del modo en el que se explica y se justifica. De tal forma, se analizan las claves discursivas que determinan las ideas de los «anfitriones» (no de los turistas) en la muestra de municipios citados en el apartado anterior, seleccionados por ser los de mayor peso demográfico y con mayor número de viviendas secundarias de las comarcas alicantinas que miran al mar².

1. La variabilidad en el origen de estas personas, en la duración de sus estancias, así como su rechazo a ser percibidos como turistas, quedan registrados en estudios empíricos, como los realizados por Per Gustafson (2001) o bajo la dirección de Fernando Vera (1995).

2. La comarca del Alacantí se descartó, porque la dinámica creada en torno a Alicante genera una actividad no representativa de las tendencias dominantes. En la Marina Alta, Denia fue el municipio elegido (39.228 habitantes de derecho en 2003 y 23.029 viviendas secundarias en 2001). En el Bajo Vinalopó, Santa Pola es el municipio seleccionado (29.965 habitantes de derecho en 2003 y 26.569 viviendas secundarias registradas en el censo de 2001). Torrevieja es la ciudad principal del Bajo Segura (87.790 habitantes de derecho en 2003 y 80.790 viviendas secundarias en 2001). La comarca de la Marina Baja es más 
La pregunta ¿qué espera y qué obtiene del turismo la población anfitriona? (Krippendorf, 1984/1987: 44-56) es reformulada así: ¿cómo definen y valoran el turismo los residentes en las ciudades turísticas? El objetivo concreto es el estudio de los discursos producidos por cuatro fuentes clave de poder: políticos, empresarios, expertos y ciudadanía. Interesan aquí las «representaciones con capacidad para determinar la visión de la mayoría de los sectores» (Gil de Arriba, 2002: 78), por lo que se adopta una perspectiva cualitativa y se utilizan técnicas que describen, descodifican y sintetizan los significados, no las frecuencias (Van Maanen, 1983: 9). Claro, se asumen limitaciones metodológicas, pues sólo se identifican y se exploran los discursos sin pretensión de generalizar los resultados. Al respecto, y para este estudio en concreto, la cuantificación será una operación que se abordará en futuros trabajos orientados a evaluar la representatividad estadística de las ideas aquí expuestas.

Se ha "dibujado" un esquema interpretativo de las fuentes del poder en el ámbito municipal, inspirado en el modelo de planificación turística basado en la "teoría de las partes interesadas» (Sautter y Leisen, 1999: 312-328), que resulta de la interacción problemática entre los grupos citados (gráfico 1).

Se ha creído que a partir de este esquema puede trazarse un argumento de interés y que la inclusión de otros actores iba a dificultar en exceso la presentación de un hilo conductor coherente. No obstante, se remarca que este artículo debe leerse en el contexto de unos municipios turísticos maduros. La multitud de destinos emergentes puede dar lugar a realidades diferentes, como resultado de modificaciones legislativas o de la participación de actores que anteriormente no han tenido poder de decisión.

Para seleccionar a los entrevistados se combinó un muestreo intencional por cuotas y un muestreo estructural, con el fin de salvar el hecho de que los residentes no son un todo homogéneo y se supone una variabilidad discursiva en función de su pertenencia a los distintos grupos ${ }^{3}$. Se eligió la entrevista cualitativa como la técnica apropiada para recabar la información de los políticos, los agentes económicos y los expertos, y el grupo de discusión para recoger el discurso de la ciudadanía. La aplicación de los grupos viene dada por su ido-

problemática. Altea es el municipio en el que mejor se aprecia el desarrollo residencial (18.976 habitantes de derecho en 2003 y 6.555 viviendas secundarias en 2001), sin embargo, a 12 kilómetros de Altea está Benidorm, un caso único que combina el turismo hotelero con el residencial, aquí integrado en los apartamentos de las torres. Al final, se incluyó a ambos. Altea por cumplir el criterio de representatividad tipológica, criterio que no cumplía Benidorm, aunque parecía absurdo investigar el turismo en la provincia sin incluir a la ciudad turística más importante.

3. En el muestreo «estructural» los entrevistados se eligen según la posición que ocupan en el entramado de redes que conforma el sistema social. Es el caso de los políticos, empresarios hosteleros y técnicos municipales para cada uno de los municipios. Con los promotores inmobiliarios y los expertos académicos se tuvo en cuenta únicamente la condición de tener como área de trabajo fundamental la Costa Blanca. Los entrevistados pertenecientes a las elites políticas, económicas y los expertos fueron seleccionados mediante este tipo de muestreo. El establecimiento de cada una de las cuotas vino determinado por el criterio de saturación discursiva en cada una de las categorías. 


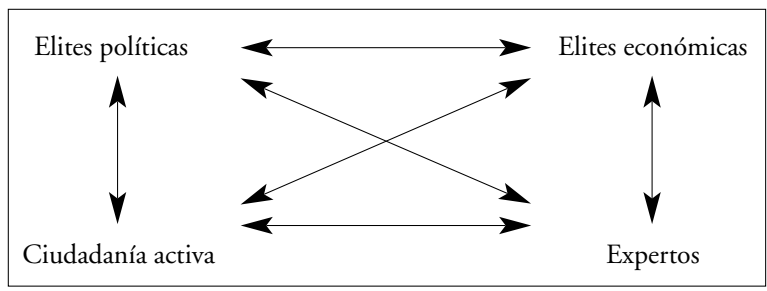

Gráfico 1. Modelo sobre las partes interesadas. Fuente: elaboración propia.

neidad para identificar los discursos expresados por los ciudadanos, a partir de la presunción de que cuando una persona no está especializada en un tema por el que está afectada necesita escuchar las opiniones de otras para formarse una opinión (Krueger, 1988: 18). Las entrevistas y los grupos se aplicaron utilizando un guión con cuestiones relacionadas con el medio ambiente, la economía, la interacción social, el modelo turístico y el cambio social ${ }^{4}$. El grupo llamado "ciudadanía activa» lo formaron los participantes en los "grupos de discusión" 5 .

El conjunto de las 37 entrevistas y los 6 grupos de discusión se realizaron entre el 1 de octubre de 2003 y el 17 de febrero de 2006. La distribución de los entrevistados fue la siguiente (tabla 3).

Después de transcribir la información recogida, la práctica del método cualitativo consta de una operación analítica y de una teórica. La primera consiste en la codificación a partir de la generación de códigos. En este estudio cada

Tabla 3. Distribución del total de los 71 entrevistados

\begin{tabular}{llllll}
\hline & $\begin{array}{l}\text { Entrevistas } \\
\text { a presidentes } \\
\text { de asociaciones } \\
\text { de hostelería }\end{array}$ & $\begin{array}{l}\text { Entrevistas } \\
\text { a empresarios } \\
\text { promotores }\end{array}$ & $\begin{array}{l}\text { Entrevistas } \\
\text { a profesores }\end{array}$ & $\begin{array}{l}\text { Entrevistas } \\
\text { a técnicos }\end{array}$ & $\begin{array}{l}\text { Número } \\
\text { de personas } \\
\text { entrevistadas } \\
\text { en los grupos }\end{array}$ \\
a concejales & y comercio & inmobiliarios & universitarios & municipales & de discusión \\
\hline 15 & 5 & 4 & 5 & 8 & 34 \\
\hline
\end{tabular}

Fuente: elaboración propia.

4. Para la identificación de estos subtemas se partió del modelo teórico sobre la «estructura conceptual del turismo» de Mathieson y Wall (1986/1990: 27).

5. Éstos no ocupaban posiciones destacadas en organizaciones y se seleccionaron a través de personas de la confianza del investigador. La expresión "ciudadanía activa» se inspira en el libro de Amitai Etzioni The Active Society (1968), en el que se presenta una crítica al anquilosamiento de las democracias de masas guiadas a través de planes diseñados por elites burocráticas. En su lugar, Etzioni proponía un modelo de consenso entre las elites técnicas y las comunidades ciudadanas comprometidas con sus objetivos. 
uno de los códigos que se identificaba era agrupado en familias de códigos (recursos, vivienda, diversión, comercio, riqueza, residuos, bienestar, corrupción, masificación, autenticidad, cosmopolitismo, etc.), y a continuación cada familia se asociaba con las secciones temáticas antes indicadas: el turista, la economía, el medio ambiente, la interacción social, el modelo turístico y el cambio social para, posteriormente, reclasificar el material reunido asociando ideas y, al final, descubrir tipologías, posicionamientos y líneas argumentales (Sandelowski, 1995: 374-375). La operación teórica consiste en la elaboración de un argumento explicativo en el que se sintetice el esfuerzo interpretativo (Valles, 1997/2003: 223). Esta segunda operación es la que se intenta realizar en las próximas líneas ${ }^{6}$.

\section{El contexto ideológico: la legitimación como hilo conductor}

A pesar de ser un área de investigación joven, en la actualidad ya existen distintas perspectivas teóricas desde las que abordar el análisis del fenómeno turístico. En el campo específico de los estudios de percepción social sobre el turismo, que es al fin y al cabo donde encuentra su lugar este artículo, pueden identificarse al menos tres orientaciones teórico-metodológicas que, desde enfoques eminentemente cuantitativos, exploran la percepción de la dinámica turística por parte de las poblaciones receptoras. Esas orientaciones son aquéllas que inciden en el estudio de 1) la percepción del perfil socioeconómico de los turistas y la segmentación de categorías de residentes (Harril y Potts, 2003; Cavus y Tanrisevdi, 2002); 2) la valoración de la ocupación de los espacios públicos (Korça, 1998; Tyrell y Spaulding, 1984), y 3) los trabajos sobre la percepción y las actitudes de los residentes realizados al amparo de la «teoría de la vinculación comunitaria», que interpreta los procesos de participación social en la vida comunitaria por parte del turista (McCool y Martin, 1994), la «teoría del intercambio social», que complementa a la teoría anterior, aunque hace mayor énfasis en las acciones en las que tienen lugar intercambio de recursos entre turistas y residentes (Getz, 1994; Madrigal, 1993) y, finalmente, la «teoría de la máquina de crecimiento", que fija su atención en la elaboración de un modelo que atienda a aquellas variables vinculadas al turismo que impulsan o frenan el desarrollo económico (Martin, McGuire y Allen, 1998; Canan y Hennessy, 1989). Pero todas estas perspectivas se asientan sobre estudios que, en su práctica totalidad, se han adentrado en la comprensión del turismo entendiendo a éste, en su sentido clásico, como una actividad sujeta inexorablemente a motivaciones vacacionales asociadas a infraestructuras hoteleras o similares. Sin embargo, no existe un marco teórico sobre lo que aquí se entiende como "proceso turístico-residencial», es decir, como una actividad que se asocia a la emergencia de nuevos estilos de vida y formas de residencialidad, con

6. El análisis intensivo y la transcripción íntegra de las entrevistas y de los grupos de discusión pueden consultarse en la tesis doctoral del autor. 
una motivación vacacional parcial, nula o sólo inicial, que se vincula a actividades urbanísticas ligadas a la construcción masiva de viviendas secundarias y que localiza su espacio de máximo apogeo mundial en la ribera norte del Mediterráneo. De este modo, resulta muy difícil establecer en qué estado se halla el esqueleto conceptual de dicho proceso y, en consecuencia, marcar con claridad los posibles puntos de partida para, "a hombros de gigantes», aportar nuevo conocimiento. No obstante, de las primeras aproximaciones que se efectuaron en la prehistoria de esta investigación, con el fin de conseguir una toma de contacto con el objeto de estudio (esencialmente, charlas informales con algunos expertos y lectura de textos fundamentales), se desprendía una idea dominante: el turismo residencial está determinado e «instrumentalizado» por una expansión inmobiliaria perjudicial para las sociedades receptoras (Mazón, 2001: 98; Vera y Marchena, 1996: 329). La más o menos clara interacción entre políticos y empresarios ha sido reconocida por la mayor parte de los entrevistados como la clave que ha determinado el devenir de un proceso caracterizado por la ausencia de planificación.

El profundo cambio social derivado del intenso proceso de modernización económica que ha resultado de la actividad turística (transición directa de economías sustentadas por el sector primario, en el área de referencia principalmente por la agricultura y la pesca, a otras que giran en torno a la construcción y los servicios) ha modificado integralmente las sociedades que hoy son destinos turístico-residenciales en la región en el marco de una insuficiente y deficiente gestión turística. Esta proposición inicial es compartida por todos los entrevistados. La primera y más importante bifurcación discursiva tiene que ver con la valoración que se hace de este proceso: el enriquecimiento económico, casi incuestionable, ha sido acompañado por desarrollos en la esfera medioambiental y cultural considerados críticos por algunos (masificación social y degradación ecológica) y positivos por otros (cosmopolitismo y revalorización del patrimonio natural). Pero esta bifurcación sólo aparentemente se materializa en un contexto ideológico dicotómico, pues no posee una trascendencia real en la práctica. La mayor parte de los entrevistados cree que el peso de los impactos socioeconómicos positivos es, con mucho, superior a cualquiera de los impactos negativos que se puedan identificar. Y esta interpretación trasciende los distintos modos o tipologías de desarrollo turísticoresidencial («de masas» $\mathrm{o}$ "de alto standing»), tras convertirse no sólo en una posición discursiva dominante, sino también en una suerte de lo que Berger y Luckmann denominaron "estructura objetivada del mundo social», destinada a ser interiorizada por las futuras generaciones. A ser uno de los principios directores del «orden institucional» que contribuyen a su «legitimación», es decir, a su explicación y justificación (Berger y Luckmann, 1966/1998: 122).

La revisión de los modos en los que se ha llevado a cabo el estudio de la legitimación desde las diversas áreas de la sociología y la ciencia política muestra que este concepto queda vinculado a la «supervivencia» de las estructuras sociales y culturales (Johnson, Dowd y Ridgeway, 2006: 53-54). A través de la explicación se concede «dignidad normativa» a los «imperativos prácticos». Es decir, 


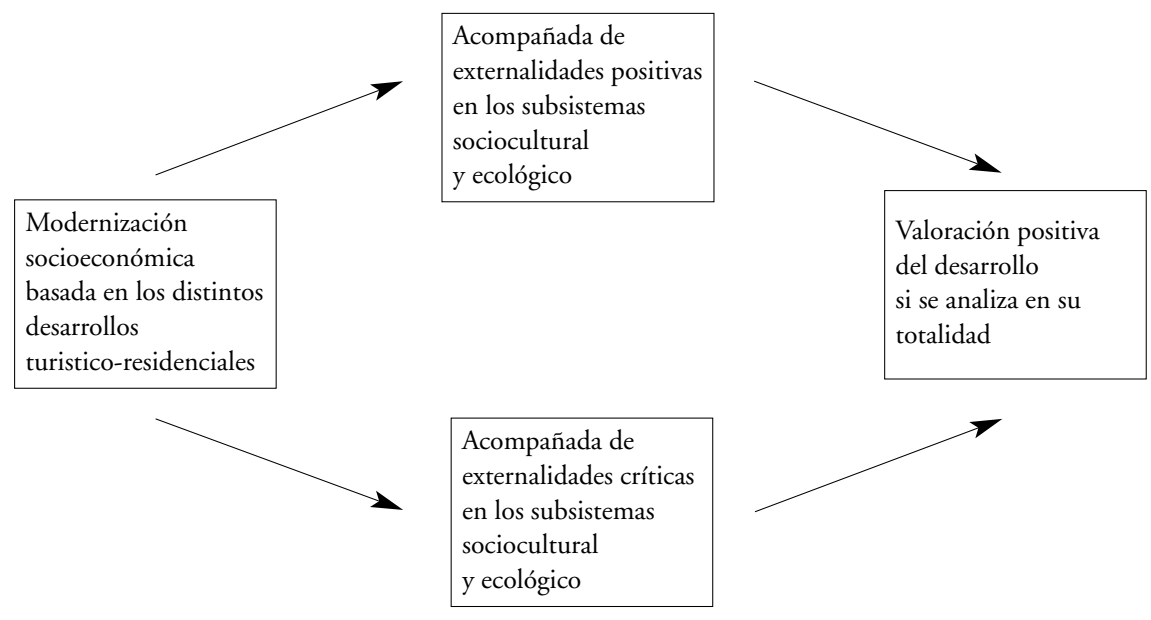

Gráfico 2. Discurso sobre los impactos de la modernización socioeconómica basada en el turismo residencial. Fuente: elaboración propia.

existen unas dimensiones cognitivas y normativas de la legitimación: «la legitimación no sólo indica al individuo por qué debe realizar una acción y no otra; también le indica por qué las cosas son lo que son. En otras palabras, el "conocimiento" precede a los "valores" en la legitimación de las instituciones» (Berger y Luckmann, 1966/1998: 122). El análisis reveló que la legitimación del proceso de desarrollo turístico-residencial en el área de referencia se encuentra en algún lugar entre el segundo y el tercero de los cuatro niveles de legitimación propuestos por Berger y Luckmann, es decir, entre aquél que se caracteriza por la articulación de esquemas explicativos simples, muy pragmáticos, orientados a facilitar las acciones concretas, y aquél otro en el que se produce un posterior refinamiento de las explicaciones hasta convertirlas en teorías explícitas (Berger y Luckmann, 1966/1998: 122-125). Cathryn Johnson, Timothy J. Dowd y Cecilia L. Ridgeway (2006: 59-73) también distinguen cuatro etapas de legitimación: «innovación», "validación local», «difusión» y "validación general». La primera etapa ya se ha cubierto, pues la propuesta turístico-residencial hace tiempo que se configuró como una opción de desarrollo factible; la segunda también, porque dicha propuesta, como prueba el paso del tiempo, ha tenido una implantación espectacular en numerosas comunidades costeras; el presente coincide con un momento crucial entre la tercera y la cuarta etapas, ya que el modelo prácticamente se ha exportado a toda la franja litoral mediterránea y ahora - cuando en la costa ya casi no queda territorio- busca desarrollarse en el interior (como apuntaban Mas y Goerlich en la cita que iniciaba este texto) y, se añade aquí, en las provincias del norte, con escasa tradición de turismo de masas. A la espera de lo que ocurra en los próximos años con esos nuevos desarrollos, el estado de «validación general» está todavía por llegar. Ernesto Laclau 
(1990: 39-41) había profundizado en estas ideas para explicar que es en los procesos de identificación de la ciudadanía con ciertos proyectos políticos donde se articulan los diferentes posicionamientos ideológicos. Procesos que, una vez estabilizados, convierten a las personas en actores sociales con unas características y unos atributos concretos. De tal modo, como se ve en el cuadro 1, puede identificarse un "contexto ideológico desarrollista» sustentado sobre una serie de posiciones ideológicas bajo las cuales se agrupan estructuras discursivas específicas. Por "contexto ideológico desarrollista», y en el marco de este estudio, se ha entendido un área social en el que los discursos más próximos a ocupar una posición de "hegemonía» son aquéllos que promulgan una idea de "crecimiento» indisociable a la idea de «riqueza» y «bienestar», en virtud de la cual los costes socioculturales y principalmente medioambientales que dicho crecimiento lleva aparejado se aceptan como asumibles, ya sea por una motivación sostenida en el convencimiento en los beneficios que genera, ya sea por estar la sociedad envuelta en una atmósfera de resignación hacia la realidad existente y de desconfianza ante modos alternativos de garantizar el equilibrio del sistema. Los límites, el ritmo y el modo de ese crecimiento son objeto de debate en los distintos municipios, pero no lo es la idea de continuar creciendo sobre las bases del modelo ya conocido.

El concepto de "hegemonía» (popularizado por Antonio Gramsci para el análisis de las ideologías y los discursos sociales) es retomado por Laclau y Mouffe (1985: 136-142) para dar cuenta de situaciones en las que diferentes proyectos políticos en competencia, y con fronteras ideológicas difusas, se esfuerzan por producir discursos que den una explicación acabada sobre determinados hechos sociales, con el fin de alcanzar una posición hegemónica mediante la consolidación de sistemas de significados capaces de lograr la adscripción de la mayoría de los sectores sociales. Las estructuras discursivas presentadas a continuación aglutinan el núcleo de los discursos, más o menos críticos, acerca del significado del turismo residencial. La «lucha» por dar forma a un discurso hegemónico enfrenta a políticos de todos los partidos, empresarios, residentes y expertos. Todos son conscientes de que el discurso hegemónico se materializa en una guía a partir de la cual es posible articular planes de desarrollo turístico y de sostenibilidad urbana. En el cuadro 1 se reflejan cinco posiciones ideológicas típicas, identificadas tras completar la operación analítica antes apuntada, que se corresponden con cinco modos de interpretar la realidad social y turística. La interacción de unas y otras conforman el estado de la opinión y del discurso público en el contexto del sistema turístico-residencial, si bien los límites entre ellas no se muestran claramente, por lo que un mismo agente social aparece con frecuencia vinculado a diferentes posiciones.

Las posiciones 2 y 3 , que aquí se han denominado "posición permisiva» y "crítica parcial-legitimadora", dan forma a los discursos principales (mainstream discourses), producidos por la mayor parte de los entrevistados:

$\mathrm{La}$ "posición permisiva" agrupa a quienes creen que el turismo residencial es el resultado natural de una respuesta a una determinada demanda del mer- 


\section{Cuadro 1. Cuadro semiótico-estructural de las posiciones ideológicas respecto al turismo residencial en el contexto de la Costa Blanca de Alicante}

\begin{tabular}{|c|c|c|c|c|}
\hline \multicolumn{2}{|l|}{ Legitimación } & \multicolumn{2}{|l|}{ Crítica } & \multirow{2}{*}{$\begin{array}{l}\text { Negación } \\
\text { 5. Posición radical }\end{array}$} \\
\hline $\begin{array}{l}\text { 1. Defensa } \\
\text { incondicional }\end{array}$ & 2. Posición permisiva & $\begin{array}{l}\text { 3. Crítica parcial, } \\
\text { legitimadora }\end{array}$ & $\begin{array}{l}\text { 4. Crítica total, no } \\
\text { legitimadora }\end{array}$ & \\
\hline $\begin{array}{l}\text { Diagnóstico: } \\
\text { Modelo turístico } \\
\text { regulado por la ley de } \\
\text { oferta y demanda. }\end{array}$ & $\begin{array}{l}\text { Diagnóstico: } \\
\text { Modelo turístico } \\
\text { regulado por la ley de } \\
\text { oferta y demanda. }\end{array}$ & $\begin{array}{l}\text { Diagnóstico: } \\
\text { Modelo turístico } \\
\text { regulado por la ley de } \\
\text { oferta y demanda y por } \\
\text { los intereses de los } \\
\text { empresarios } \\
\text { constructores. }\end{array}$ & $\begin{array}{l}\text { Diagnóstico: } \\
\text { Modelo turístico- } \\
\text { urbanístico determinado } \\
\text { por los intereses de } \\
\text { constructores y } \\
\text { promotores en sintonía } \\
\text { con los responsables } \\
\text { políticos. }\end{array}$ & $\begin{array}{l}\text { Diagnóstico: } \\
\text { El llamado modelo } \\
\text { turístico-residencial no es, } \\
\text { en realidad, un modelo } \\
\text { turístico, sino una } \\
\text { actividad especulativo- } \\
\text { urbanística basada en la } \\
\text { explotación del espacio. }\end{array}$ \\
\hline $\begin{array}{l}\text { Valoracion: } \\
\text { Positivo. Dinamismo } \\
\text { socioeconómico } \\
\text { beneficioso para el } \\
\text { conjunto de los agentes } \\
\text { sociales implicados. No } \\
\text { hay problemas } \\
\text { fundamentales. }\end{array}$ & $\begin{array}{l}\text { Valoración: } \\
\text { El peso de los efectos } \\
\text { positivos (económicos, } \\
\text { esencialmente) es mayor } \\
\text { que el de los negativos } \\
\text { (ecológicos, sobre todo). }\end{array}$ & $\begin{array}{l}\text { Valoración: } \\
\text { Situación compleja. No } \\
\text { se puede afirmar con } \\
\text { rotundidad que el } \\
\text { balance es en su } \\
\text { conjunto positivo o } \\
\text { negativo. Ante la duda } \\
\text { lo positivo pesa más. } \\
\text { El crecimiento turístico } \\
\text { no se ha producido al } \\
\text { mismo ritmo que el } \\
\text { desarrollo de la red de } \\
\text { infraestructuras } \\
\text { necesarias. }\end{array}$ & $\begin{array}{l}\text { Valoración: } \\
\text { Agresión ecológica brutal. } \\
\text { Socialización de los } \\
\text { costes y privatización de } \\
\text { los beneficios en pocas } \\
\text { manos (constructores, } \\
\text { inmobiliarias y políticos } \\
\text { corruptos). } \\
\text { Empobrecimiento del } \\
\text { sector hostelero. }\end{array}$ & $\begin{array}{l}\text { Valoración: } \\
\text { Agresión ecológica brutal. } \\
\text { Masificación muy } \\
\text { negativa. Conflictos } \\
\text { intergrupales latentes. } \\
\text { Estafas inmobiliarias } \\
\text { constantes que, al final, } \\
\text { atraen a mafias criminales. } \\
\text { La culpa es de todos, } \\
\text { también de la ciudadanía } \\
\text { que legitima el modelo. }\end{array}$ \\
\hline $\begin{array}{l}\text { Terapia: } \\
\text { Optimismo. Continuar } \\
\text { con el modelo } \\
\text { ampliando la oferta de } \\
\text { ocio, la red de } \\
\text { infraestructuras y } \\
\text { minimizando los } \\
\text { impactos ambientales. } \\
\text { Convivencia positiva } \\
\text { con el turismo hotelero. }\end{array}$ & $\begin{array}{l}\text { Terapia: } \\
\text { Optimismo. El futuro } \\
\text { está en el turismo. } \\
\text { Captación de turistas } \\
\text { con recursos económicos } \\
\text { altos. Ampliar la oferta } \\
\text { de ocio e } \\
\text { infraestructuras. } \\
\text { Minimizar el impacto } \\
\text { ambiental. } \\
\text { Complementar con } \\
\text { turismo hotelero. }\end{array}$ & $\begin{array}{l}\text { Terapia: } \\
\text { Optimismo y } \\
\text { escepticismo. El futuro } \\
\text { está en el turismo, pero } \\
\text { hay que cambiar la } \\
\text { planificación urbana. } \\
\text { Crear infraestructuras y } \\
\text { una red de servicios y } \\
\text { ocio de calidad. } \\
\text { Minimizar el impacto } \\
\text { ambiental. } \\
\text { Complementar con } \\
\text { turismo hotelero. }\end{array}$ & $\begin{array}{l}\text { Terapia: } \\
\text { Escepticismo y } \\
\text { pesimismo. Detener el } \\
\text { crecimiento. Pocas } \\
\text { alternativas. Mejorar la } \\
\text { situación presente con } \\
\text { inversiones en } \\
\text { infraestructuras y } \\
\text { servicios sociales. } \\
\text { Complementar con } \\
\text { turismo hotelero, si es } \\
\text { que aún es posible. }\end{array}$ & $\begin{array}{l}\text { Terapia: } \\
\text { Escepticismo y pesimismo. } \\
\text { Detener el crecimiento de } \\
\text { inmediato. Apenas hay } \\
\text { alternativas (demasiado } \\
\text { tarde). Reordenación en el } \\
\text { contexto de un margen de } \\
\text { maniobras muy limitado. }\end{array}$ \\
\hline $\begin{array}{l}\text { Representantes: } \\
\text { PP, promotores. }\end{array}$ & $\begin{array}{l}\text { Representantes: } \\
\text { Ciudadanía, PP, PSOE, } \\
\text { partidos nacionalistas e } \\
\text { independientes, técnicos } \\
\text { municipales, expertos } \\
\text { académicos. }\end{array}$ & $\begin{array}{l}\text { Representantes: } \\
\text { Ciudadanía, PSOE, } \\
\text { partidos nacionalistas e } \\
\text { independientes, } \\
\text { expertos académicos, } \\
\text { asociaciones de } \\
\text { hostelería. }\end{array}$ & $\begin{array}{l}\text { Representantes: } \\
\text { IU, Verdes, expertos } \\
\text { académicos, asociaciones } \\
\text { de hostelería. }\end{array}$ & $\begin{array}{l}\text { Representantes: } \\
\text { Verdes, expertos } \\
\text { académicos. }\end{array}$ \\
\hline
\end{tabular}

Fuente: elaboración propia a partir de Mantecón (2005: 405). 
cado. Opinan que se han cometido errores a causa de una falta de planificación del desarrollo, pero ésta sería una crítica muy fácil de hacer desde el presente. El incremento del bienestar socioeconómico de las poblaciones receptoras es evidente (a través de los efectos de arrastre positivos), aunque reconocen impactos medioambientales que, sin embargo, no empañan el valor positivo general. Las propuestas de trabajo se dividen en tres líneas: a) la inversión en infraestructuras; $b$ ) la diversificación de la oferta de ocio y complementación con el turismo hotelero, y $c$ ) la vinculación del turismo residencial a un turista de elevados recursos económicos (no es posible un turismo residencial de masas). En la que se ha llamado "crítica parcial-legitimadora», el modelo no responde únicamente al laissez faire, pues se considera que los intereses privados de los empresarios (promotores sobre todo) y los dirigentes políticos locales intervienen decisivamente. Desde esta posición, la crítica se centra en los impactos medioambientales, el desorden urbanístico y una masificación que habría perjudicado la vida social. La situación se valora como muy compleja, al tiempo que se reconoce la imposibilidad de hacer valoraciones reduccionistas. Se han cometido muchos errores, pero en la balanza lo positivo pesa más que lo negativo. El turismo se estima como la industria fundamental en la que asentará el futuro y no se vislumbran otras opciones realmente sólidas. Pero se reconoce la necesidad de cambiar la planificación urbana, crear una red de infraestructuras, diversificar y mejorar la calidad de la oferta de ocio, minimizar el impacto ambiental y promover un mayor desarrollo del sector hotelero, que es valorado como más sostenible.

La lectura del cuadro muestra que el turismo residencial es interpretado como un fenómeno beneficioso para las sociedades receptoras por la mayoría de los agentes implicados, con independencia de que el análisis empírico de los impactos reales ofrezca un balance positivo o crítico, de que exista, como indicaba Jürgen Habermas (1973), una «crisis de racionalidad» (incapacidad del subsistema político-administrativo para gestionar el conjunto de recursos y de actividades sin poner en peligro el equilibrio del conjunto del sistema), porque la mayor parte de las personas que ocupan posiciones de centralidad en la dirección y en la valoración del desarrollo social y turístico en el contexto de estas sociedades definen la situación como beneficiosa o, en su defecto, necesaria. Este último matiz no tiene mayores implicaciones prácticas. Tampoco importa si se trata con "hombres verdaderamente culturales» o con "hipócritas culturales», clasificación de la que Freud se servía para hacer una distinción entre aquellas personas que interiorizan y asumen unos determinados valores de aquéllas otras que simplemente los aceptan y los consienten porque les resulta más ventajoso desde un punto de vista meramente pragmático (Freud, 1915/1990: 106-107). Las posiciones de resistencia o la formulación de alternativas auténticas no surgen de ellas. No existiría, siguiendo con el modelo explicativo de Habermas, una "crisis de legitimación» (incapacidad del subsistema político-administrativo para alcanzar el nivel de lealtad ciudadana requerido). Conviene anotar, al hilo de la "crisis de racionalidad", que muchos entrevistados — provenientes de diferentes ámbitos_ manifestaron su reticencia 
a creer que existan actualmente elementos de juicio suficientes como para diagnosticar claramente la existencia de esa crisis. Las opiniones que insistentemente se orientaban al ensalzamiento del progreso económico respaldado por la conservación de reservas ecológicas (susceptibles de ser promocionadas mercadotécnicamente) apuntaban en ese sentido. Igualmente, algunos entrevistados mostraron la dificultad de tomar en consideración investigaciones en las que se demuestre nítidamente que, en términos estrictamente económicos, los desarrollos turístico-residenciales son más o menos rentables que los hoteleros.

El turismo ha convertido la virtud de la hospitalidad en un negocio (Krippendorf, 1984/1987: 44) que, en ocasiones, se convierte en la fuente de ingresos fundamental de muchas familias. Es decir, crea situaciones en las que la mejora del bienestar social aparece ligada a la dependencia turística. Aquí, la percepción de los procesos macrosociales se funde con la autopercepción de los cambios que acontecen en la vida de los individuos, por lo que entran en juego variables psicosociales muy difíciles de medir que tienen que ver con lo que Peter L. Berger denominó «alternación» (1963: 54 y s.). Ante esta situación, resulta que los esfuerzos de algunos investigadores críticos por trasmitir los resultados y las reflexiones que surgen del estudio empírico de los procesos que generan la supuesta «crisis de racionalidad» no tienen demasiado éxito. Los políticos, conocedores de todo este entramado, saben que el coste que resultaría de una modificación parcial o total de los parámetros del desarrollo turístico a menudo no les compensa, pues el rendimiento electoral no es en absoluto evidente. Las variaciones sobre la sostenibilidad de los desarrollos turísticos existentes en el litoral alicantino quedan soterradas por un denominador común: el éxito que cada uno de esos desarrollos ha cosechado en su mercado electoral interno. No es la sostenibilidad del modelo lo que garantiza el éxito de su perpetuación, sino el hecho de que la población local percibe que ha mejorado su situación material gracias a un fenómeno ante el que no se presentan alternativas de desarrollo (de "progreso») convincentes, lo demás queda en un segundo plano. Es ésta una cuestión que contribuye a explicar por qué la práctica totalidad de los entrevistados afirma que, gracias al especial carácter acogedor de los residentes en las ciudades mediterráneas, no existe ningún atisbo de conflicto, y que la marcada ausencia de interacción en muchas localidades sea vista desde el respeto y sin connotaciones problemáticas.

Los lentos avances que se han producido en los últimos tiempos en las demandas, tanto de los turistas como de los propios residentes, a partir de la acentuación del discurso crítico de algunos de los partidos políticos opositores (conocedores, en el mejor de los casos, de la literatura crítica producida por una parte de los expertos) se encuentran lejos de llegar a ocupar posiciones discursivas hegemónicas.

En la terminología clásica de la ecología humana (Park, 1936: 1-15), podría decirse que dos de los elementos de la «comunidad» se renuevan: la "población" y la "cultura tecnológica»; y dos no lo hacen: el «espacio natural» y la «cultura no material». Este último elemento es el que se ha tratado de explo- 
rar. Si, como afirman algunos expertos, la crisis de racionalidad fuese un hecho ya constatable en el sistema turístico-residencial (Mazón, 2006: 96-97 o Aledo, 2005: 176-177), de continuarse con las dinámicas de crecimiento actuales, tarde o temprano se llegará a una situación final cercana a la saturación en la que la "cultura tecnológica» tendrá poco margen de actuación. Esas dinámicas se relacionan con el progresivo agotamiento de un recurso escaso: el suelo. Esto es, con un problema estructural cuyas posibles soluciones no pasarán ya por la innovación en el campo de la "cultura tecnológica", sino en el de la "cultura no material» de las creencias y las costumbres. A la luz de las características de las posiciones ideológicas dominantes identificadas y exploradas, parece que la "cultura no material» no muestra síntomas claros que permitan pensar en grandes cambios a corto plazo. Entonces, es posible que, en cuestión de no demasiado tiempo, llegue la etapa legitimadora de «validación general» a la que se hacía referencia.

\section{A modo de conclusión: nuevas líneas de trabajo}

La aportación de este artículo consiste en una reformulación, en concreto, en una propuesta de nueva orientación de los trabajos de investigación empírica sobre los desarrollos turístico-residenciales en el Mediterráneo español, y muy especialmente de aquéllos que, ya sea desde una perspectiva cuantitativa, cualitativa o mixta, abordan la cuestión de la percepción social, teniendo en cuenta que resulta de gran importancia considerar la posibilidad de que exista un "contexto ideológico desarrollista» en el que los discursos de legitimación tengan una presencia mayor que los discursos que promulgan la crítica o la resistencia social, al menos entre las "partes interesadas» que tradicionalmente han tenido una capacidad real de decisión en las sociedades receptoras. Aquí se ha intentado demostrar que este proceso de urbanización turística, y para la región de referencia (con atención específica a los municipios turísticos consolidados), también ha tenido lugar en los márgenes de un contexto ideológico legitimador y sustentado por el conjunto de la sociedad. Un contexto que, debe subrayarse, viene configurado históricamente (Mantecón, 2005: 396-402). Sin embargo, el estudio de la legitimación social como factor cultural explicativo no ha sido suficientemente estudiado, a pesar de que puede ayudar a entender por qué el ocio turístico asociado a la dinámica residencial-inmobiliaria ha dado lugar a procesos de tanta intensidad y calado en las costas mediterráneas.

La confirmación de la perpetuación de la expansión turístico-urbanística en las costas españolas (tal y como se señalaba a propósito del trabajo antes citado de Mas y Goerlich) daría lugar, siguiendo los discursos más críticos, a lógicas contradictorias que provocarían inflación y subida del precio del suelo, impactos ambientales graves, déficits estructurales, colapso urbano e, incluso, un incremento de la inseguridad ciudadana y de los conflictos intergrupales. El resultado sería un modelo turístico que linda el agotamiento (Vera, 1994) y que genera un preocupante escenario de riesgo (Aledo, 2005). Esta visión, por 
un lado, debe tener en cuenta que hay determinadas cuestiones ante las que las personas no suelen realizar un análisis pormenorizado de los costes y los beneficios, sino que, mayormente, lo que hacen es construir una opinión general resultado de la percepción de los discursos principales que tratan el asunto, $\mathrm{y}$, por otro lado, que el análisis de la interacción entre turistas y locales se inscribe en la tradición heredada de los pesimistas resultados obtenidos en distintas partes del mundo a través de multitud de estudios socioantropológicos en los que se constata la decepción sufrida habitualmente por los "anfitriones» en su experiencia del turismo (Castaño, 2005: 200-213). Sin embargo, conviene indicar que una parte considerable de esos estudios, de corte antropológico, se han realizado en el seno de sistemas sociales en los que, o bien la dependencia económica de la actividad turística no es tan evidente, o las desigualdades son muy agudas, por lo que no existe nada parecido a lo que pudiera entenderse como una estructura de clases medias y/o una red de mecanismos para socializar, además de los costes, al menos una parte de los beneficios.

La perspectiva metodológica cualitativa adoptada ha permitido abrir una ventana al contexto ideológico y el análisis de los datos recopilados ha dado como resultado la identificación de un mapa básico de posicionamientos, de utilidad para comprender el papel que desempeña la legitimación social en el desarrollo del proceso turístico-residencial e, igualmente, de utilidad para anclar un punto de partida en próximos estudios cuantitativos dedicados a medir la representatividad estadística de las ideas expuestas.

\section{Referencias bibliográficas}

Aledo, A. (2005). «Los otros inmigrantes: residentes europeos en el sudeste español». En: FERNÁNDEZ, J.; GARCÍA, M. (eds.). Movimientos migratorios contemporáneos. Murcia: Universidad Católica San Antonio.

Berger, P. L. (1963). Invitation to Sociology. A Humanistic Perspective. Nueva York: Anchor Books.

BERGER, P. L.; LuCKMANN, T. (1966). La construcción social de la realidad. Buenos Aires: Amorrortu, ed. de 1998.

Bote, V.; MARChENA, M.; SANTOS, E. (1999). «La descentralización autonómica y la diversificación de la estrategia de desarrollo turístico (1974-1998)». En: PELLEJERO, C. (dir.). Historia de la economía del turismo en España. Madrid: Editorial Civitas.

CANAN, P.; HenNESSY, M. (1989). "The growth machine, tourism, and the selling of culture». Sociological Perspectives, 32 (2): 227-243.

Castaño, J. M. (2005). Psicología social de los viajes y del turismo. Madrid: Thomson.

CAVUS, S.; TANRISEVDI, A. (2002). «Residents attitudes toward tourism: A case study of Kusadasi, Turkey». Tourism Analysis, 7 (3-4): 259-268.

CORTINA, F.; MARTíneZ, A.; VARELA, B. (2002). «Aproximación a la investigación del alojamiento privado de uso turístico». Estudios turísticos. Instituto de Estudios Turísticos, 151: 87-97.

FERRAS, C. (2000). «Ciudad dispersa, aldea virtual y revolución tecnológica. Reflexiones acerca de sus relaciones y significado social». Scripta Nova. Revista electrónica de geografía y ciencias sociales. Universidad de Barcelona, vol. IV, núm. 69 (68), 1 de agosto. En: <http://www.ub.es/geocrit/sn-69-68.htm>. 
FREUD, S. (1915). «Consideraciones de actualidad sobre la guerra y la muerte». En: El malestar en la cultura y otros ensayos. Madrid: Alianza, ed. de 1990.

GETZ, D. (1994). «Residents' attitudes towards tourism: A longitudinal study of Spey Valley, Scotland». Tourism Management, 15 (4): 247-258.

Gil de ArRiBA, C. (2002). Ciudad e imagen. Santander: Universidad de Cantabria. Gustafson, P. (2001). «Retirement migration and transnational lifestyles». Ageing and Society, 21 (4): 371-394.

Habermas, J. (1973). Problemas de legitimación en el capitalismo tardio. Buenos Aires: Amorrortu, ed. de 1975.

HARRILl, R.; POTTS, T. D. (2003). «Tourism planning in historic districts: Attitudes toward tourism development in Charleston». Journal of the American Planning Association, 69 (3): 233-244.

IrIBAS, J. M. (2000). «Benidorm, manual de uso». En: MVRDV. Costa ibérica. Hacia la ciudad del ocio. Barcelona: ACTAR DL.

Johnson, C.; DowD, T. J.; RidGeWAY, C. L. (2006). «Legitimacy as a Social Process». Annual Review of Sociology, 32: 53-78.

KORÇA, P. (1998). «Resident perceptions of tourism in a resort town». Leisure Sciences, 20 (3): 193-212.

KRIPPENDORF, J. (1984). The Holiday Makers. Understanding the impact of leisure and travel. Londres: Heinemann, ed. de 1987.

Krueger, R. A. (1988). Focus Groups: A Practical Guide for Applied Research. Newbury Park, CA: Sage.

LaClau, E. (1990). New Reflections on the Revolution of Our Time. Londres: Verso. Laclau, E.; Mouffe, C. (1985). Hegemony and Socialist Strategy. Londres: Verso. LOPEZ DE LERA, D. (1995). «La inmigración en España a finales del siglo XX. Los que vienen a trabajar y los que vienen a descansar». Revista Española de Investigaciones Sociológicas, 71-72: 225-245.

MADRIgAL, R. (1993). "A tale of tourism in two cities». Annals of Tourism Research, 20 (2): 336-353.

MANTECÓN, A. (2005). «La construcción social de la experiencia turística: el caso de los anfitriones». En: MAZÓN, T.; AlEDO, A. (eds.). Turismo residencial y cambio social. Nuevas perspectivas teóricas y empiricas. Alicante: Aguaclara.

Martin, B.; MCGuire, F.; Allen, L. (1998). «Retirees' attitudes toward tourism: Implications for sustainable development». Tourism Analysis, 3 (1): 43-51.

Mas, M.; Goerlich. F. (2006). La localización de la población española sobre el territorio. Un siglo de cambios: un estudio basado en series homogéneas (1900-2001). Bilbao: Fundación BBVA.

- (2006b). «No se ve un final a la demanda de la costa». Diario Información, domingo, 11 de junio.

MathiesOn, A.; Wall, G. (1986). Turismo. Repercusiones económicas, físicas y sociales. México: Trillas, ed. de 1990.

MAZÓn, T. (2001). Sociología del Turismo. Madrid: Editorial Centro de Estudios Ramón Areces.

- (2002). «Los problemas del turismo inmobiliario en el litoral alicantino», documento de trabajo presentado en el I Ciclo de Conferencias «Sociedad y medio ambiente, temas de nuestro tiempo». Altea: Fundación Ciencias Sociales y Mundo Mediterráneo y Fundación Biodiversidad, 7-9 de noviembre.

- (2006). «Inquiring into Residential Tourism: The Costa Blanca Case». Tourism and Hospitality Planning and Development, 3 (2): 89-97. 
MAZÓN, T.; Aledo, A. (2005). «El dilema del turismo residencial: ‘turismo o desarrollo inmobiliario». En: MAZÓN, T.; ALEDO, A. (eds.). Turismo residencial y cambio social. Nuevas perspectivas teóricas y empíricas. Alicante: Aguaclara.

MCCOOL, S. F.; MARTIN, S. R. (1994). "Community attachment and attitudes toward tourism development». Journal of Travel Research, 32 (2): 29-34.

O'Reilly, K. (2000). The British on the Costa del Sol. Transnational identities and local communities. Londres: Routledge.

PARK, R. E. (1936). «Human Ecology». American Journal of Sociology, 42: 1-15.

RodríGUEZ, V. (2004). «Turismo residencial y migración de jubilados». En: AUREOLES, J. (coord.). «Las nuevas formas de turismo», monográfico de la revista Mediterráneo Económico, no 5 . Caja Rural Intermediterránea. Cajamar.

SAlVÀ, P. (2005). «Procesos, pautas y tendencias del turismo residencial en las Islas Baleares: ¿̇inmigrantes de lujo o turistas de larga estancia?». En: MAZÓN, T.; ALEDO, A. (eds.). Turismo residencial y cambio social. Nuevas perspectivas teóricas y empiricas. Alicante: Aguaclara.

SANDELOWSKI, M. (1995). "Qualitative Analysis: What It Is and How to Begin». Research in Nursing \& Health, 18: 371-375.

SautTer, E. T.; Leisen, B. (1999). «Managing Stakeholders. A Tourism Planning Model». Annals of Tourism Reseach, 26 (2): 312-328.

SCHRIEWER, K.; GARCÍA, M. (2005). «Entre europeos: acerca de una posible conciencia europea. El caso de residentes europeos en España». En: FERNÁNDEZ, J.; GARCíA, M. (eds.). Movimientos migratorios contemporáneos. Murcia: Universidad Católica San Antonio.

TYRELL, T. J.; SPAULDING, I. A. (1984). «A survey of attitudes toward tourism growth in Rhode Island». Hospitality Education and Research Journal, 8 (2): 22-33.

URRY, J. (2002). «Mobility and proximity». Sociology, 36 (2): 255-274.

VAlles, M. S. (1997). Técnicas cualitativas de investigación social. Reflexión metodológica y práctica profesional. Madrid: Síntesis, ed. de 2003.

Van MaAnen, J. (ed.) (1983). Qualitative Methodology. Beverly Hills, CA: Sage.

VERA, F. (1994). «El modelo turístico del Mediterráneo español: agotamiento y estrategias de reestructuración». Papers de Turisme, 14-15: 131-148. Valencia: Institut Turístic Valencià.

- (1995). Programa de revitalización de municipios con turismo residencial (MUNRES). Alicante: Diputación Provincial de Alicante.

VERA, J. F.; MARCHENA, M. (1996). «El modelo turístico español: perspectiva económica y territorial». En: PEDREÑO, A. (dir.). Introducción a la economía del turismo en España. Madrid: Editorial Civitas. 